\title{
MACHOS OU MASCULINOS? UM ESTUDO SOBRE CONSTRUÇÕES DE MASCULINIDADES E PRODUÇÃO DE CONDUTAS VIOLENTAS.
}

\author{
Maria do Amparo Rocha Caridade ${ }^{1}$ Helena Maria D. G. Raposo ${ }^{2}$ Ana Patrícia L. \\ Freire Lopes ${ }^{3}$ \\ MALE OU MASCULINE? A STUDY ON THE CONSTRUCTION OF \\ MASCULINITIES AND THE PRODUCTION OF VIOLENT BEHAVIOR
}

\begin{abstract}
Você chama de violenta as águas de um rio que tudo arrastam; mas não chama de violentas as margens que o aprisionam (Bertold Brecht)
\end{abstract}

\begin{abstract}
Resumo: Este artigo baseia-se em uma pesquisa realizada na Universidade Católica de Pernambuco, em 2004, através do Programa Institucional de Base de Iniciação Científica, que teve como objetivos identificar relações entre modelos culturais de ser homem, a subordinação dos jovens a tais modelos e a produção de condutas violentas. Observou-se como modelos referenciais de masculinidade foram transmitidos socialmente ao longo de gerações, e que alterações foram propiciadas para a construção da subjetividade dos homens. Participaram desta pesquisa, 10 jovens, entre 20 e 30 anos. Trabalhou-se com Histórias de Vida, considerando-se que, através dessas narrativas, os sujeitos podem manifestar mais claramente os códigos, esquemas, e modelos que contribuíram para a construção de suas masculinidades. $\mathrm{Na}$ análise das narrativas buscamos identificar suas relações com os modelos culturais existentes. Os dados obtidos indicam que, para estes jovens, há satisfação com as construções da sua masculinidade, ficando clara porém uma insatisfação quanto aos modelos que subsidiaram estas construções.
\end{abstract}

Palavras-chave: Ser homem. Modelos culturais. Subordinação. Condutas violentas.

\begin{abstract}
This article is based on a research made by the Universidade Católica de Pernambuco in 2004, through the Scientific Iniciation Institucional Program. The main objectives were to identify relations between cultural models of being man, the subordination of the young men to behavior. Such models and the production of violent behavior. It was observed how masculinity reference models were socially transmitted through generations and for the construction of men subjectivity. Ten young men, aging between 20 and 30 years old, took part in this research. Histories of life were studied, considering that, through these histories, the men can more clearly reveal the codes, schemes and models that contributed to the construction of their masculinity. Analyzing the histories we seeked to identify their relation to current cultural models. Data gathered indicate that these young men are satisfied with their masculinity construction, however, there is a clear lack of satisfaction with the models that enabled this construction.
\end{abstract}

Keywords: Being men. Cultural models. Subordination. Violent behavior.

\footnotetext{
- Artigo publicado na Revista Brasileira de Sexualidade Humana, 16(1), 2005, p. 113-22. São Paulo: Iglu, 2005.

${ }^{1}$ Psicóloga. Mestre em Antropologia. Professor Adjunto da UNICAP. Coordenadora do Curso de Especialização em Sexualidade Humana da Universidade Católica de Pernambuco UNICAP.

${ }^{2}$ Psicóloga. e-mail: helena_diu@hotmail.com

${ }^{3}$ Psicóloga. e-mail: patricia_fau@hotmail.com
} 


\title{
Introdução
}

Em diversas culturas, construíram-se mitos em torno do falo como sendo sinônimo de poder, e esta concepção foi sendo difundida e naturalizada de modo que, até hoje, homens e mulheres a carregam com prestígio ou com insatisfação.

Nos primórdios da humanidade, atividades de caça e guerra eram listadas como habilidades masculinas. Do mesmo modo, a capacidade de maternagem, a fertilidade, a capacidade reprodutiva e a resistência ao parto, eram habilidades tidas como femininas. Essa divisão primordial dos papéis sexuais influenciou a produção cultural acerca de gênero e os modos de comportar-se enquanto homens e mulheres.

As idéias acerca do ser homem mantiveram-se por muito tempo associadas à maior força física presente no corpo masculino. Com o desenvolvimento tecnológico da Revolução Industrial, foi se exigindo cada vez menos habilidades ligadas à força física masculina. Com o movimento feminista, houve um redimensionamento do ser mulher e isso possibilitou um progresso em relação às questões da subjetividade feminina.

Na matéria intitulada A Construção da Masculinidade, Ceccarelli (1998) afirma que foi Freud quem primeiro se preocupou com a alma do pênis. Afirmava que o pênis era o órgão fundamental na formação do caráter de todas as pessoas. Nas mulheres pela ausência e a inveja do falo, nos homens pelo medo da castração e pelo Complexo de Édipo.

Diante do mundo globalizado no qual se vive e com a queda de barreiras entre culturas, presenciamos mudanças nos valores culturais, fazendo com que se questione os modelos referenciais de masculinidade transmitidos socialmente ao longo de gerações.

Sócrates Nolasco (1993, p. 18) considera que:

\begin{abstract}
"Um pequeno número de homens brasileiros, individualmente, começa a repensar como constroem seus vínculos afetivos e de trabalho fora do crivo do estereótipo social para eles definido. Esses indivíduos buscam encontrar caminhos próprios para sua vida, ampliando-os para além da redução a que ficaram submetidos pelo patriarcado que separa a vida de um homem da vida de um macho. Neste sentido procuram compreender as razões que os fizeram adotar um padrão de comportamento a que obedecem cegamente. Como conseqüência, os homens reproduzem os valores de um modelo social que os tutela e controla seus desejos. Tal controle é mantido pela simplificação a que fica remetida a subjetividade, bem como por meio de uma compreensão biológica de sua existência".
\end{abstract}

Considerando o desafio educacional vivido pelos meninos na adolescência Cuschnir (2001, p.49) refere-se ao código dos meninos, dizendo que eles aprendem esse código nos primeiros 
momentos da infância, quando freqüentam playgrounds, parquinhos, salas de aula, acampamentos, festinhas e reuniões. E enuncia:

\begin{abstract}
"Segundo esse receituário que oferece os fundamentos das diversas máscaras de que o homem se utilizará ao longo de toda a vida, há quatro imperativos a serem seguidos:

1. Os homens devem ser estóicos, heróicos, estáveis e independentes[...] Não podem mostrar fraqueza e nem compartilhar suas emoções com ninguém. 2. os meninos tem que ser sólidos como rocha[...] O homem deve mostrar-se impassível e inabalável. 3. As situações que a vida apresenta têm de ser encaradas como o momento de decisão[...] os meninos liberam de modo extremado sua agressividade e agem de modo a evitar a vergonha a qualquer custo, reprimindo os sentimentos de fracasso. 4. Homem tem que ser macho! Nada de bichice: sentimentos e comportamentos afetivos, como empatia, compaixão, carinho, são entendidos como femininos, homens não devem experimentá-los e, caso os experimentem estão ameaçados em sua masculinidade, devendo considerar-se efeminados."
\end{abstract}

A partir dessas referências, buscamos reconhecer nos jovens participantes deste trabalho, as pegadas de códigos como esse que, segundo Cuschinir deverão induzir ao uso de máscaras e que em nosso modo de ver, podem servir de base para condutas endurecidas ou violentas. Compreende-se que, ao usar máscaras para dar conta de ser homem, conforme os modelos propostos, ocorre no masculino um sacrifício da sensibilidade, que pode induzir o sujeito à condutas agressivas, que a cultura reconhece e legitima como sendo uma forma desejável de ser homem.

A literatura refere que o percurso do menino até a masculinidade se constrói em um espaço político e social, através de rituais e provas de iniciação em que os homens vivem a angústia de não conseguir alcançá-la. A relação do sujeito com seu pai, ou aquele que assume este papel, será decisivo para o modo como ele terá acesso às representações simbólicas do masculino.

Neste trabalho tentamos perceber se o endurecimento posto pelo modelo de ser homem foi disparador de condutas violentas, nas relações interpessoais estabelecidas pelos jovens como também compreender, como estes percebem a construção de sua masculinidade, que grau de consciência têm da absorção dos modelos impostos e da submissão que a eles dedicam. Observamos se eles refletem ou sentem necessidade de refletir sobre os modelos nos quais enquadram suas próprias masculinidades e se eles identificam alguma crise no homem atual, não apenas no sentido aflitivo do termo, mas no sentido da possibilidade e emergência de transformação que a crise suscita.

Boris (2002) acredita que a crise do masculino diz respeito à inadequação e ao incômodo de 
muitos homens com as atitudes, com os valores e com o próprio modelo de macho do patriarcado. Para ele, muitas das manifestações de violência viril, têm como um de seus principais elementos constituintes uma reação agressivo-defensiva diante da difusa sensação pessoal de decadência sócio-cultural da dominação masculina. Isso corrobora nossa busca de condutas violentas, a partir de modelos instaurados de ser homem.

A submissão a tais modelos produz inadequações que são passíveis de serem observadas tanto na fala dos sujeitos como nas referências da literatura. Conforme Dorais (1994, p 22), certos homens recorrem a soluções que não resolvem a crise existencial que eles passam, refugiando-se no álcool ou na droga para destruir os sentimentos de desconforto, de rejeição e até mesmo a raiva que sentem pelas mulheres.

Para alcançar os objetivos deste trabalho, apoiamo-nos na Antropologia, ao identificar modelos culturais de ser homem, na Psicologia e na Psicanálise, para compreender os modos de absorção desses modelos e suas conseqüências na experiência dos sujeitos.

\section{O Olhar dos Teóricos}

O que torna um homem de fato um homem? É ser viril e não demonstrar nenhum aspecto feminino? E o que falar do ícone nordestino de virilidade, o cabra-macho e sanguinário cangaceiro Virgulino Ferreira da Silva, mais conhecido como Lampião? Pesquisas mostram que este estereótipo tão conhecido do cangaceiro aponta alguns aspectos curiosos até então desconhecidos. Virgulino foi criado pela sua avó Jocosa, gostava de ajudá-la em seus afazeres domésticos, gostava de escrever poemas e apreciava que seu amigo Cascavel, the fizesse cafunés.

Meu rifle atira cantando

Em compasso assustador Faz gosto brigar comigo Porque sou bom cantador Lampião

Até 1929 só havia homens no acampamento do cangaço, dormiam todos juntos e justificavam que era para acordar mais rápido caso a polícia chegasse. A presença feminina no cangaço foi de início mal vista pelos cangaceiros, que temiam que elas atrapalhassem e que Lampião se tornasse frouxo, efeminado ou dominado por mulheres. Mesmo com a presença feminina no cangaço, eram os homens que cozinhavam.

$\mathrm{Na}$ vida itinerante que tinham, é sabido que o bando levava sempre a máquina de costura Singer portátil junto com as armas e munições. Lampião gostava de costurar e bordava em 
suas roupas detalhes inspirados na figura do imperador francês, que ele lia em revistas de moda européia, roubadas de fazendas invadidas. Gostava de jóias, moedas de ouro, perfumes franceses, lenços de seda nos quais inscrevia suas iniciais C.V.F.L Capitão Virgulino Ferreira Lampião. Era uma pessoa sensível e chegava a escolher até o melhor e mais bonito lugar para acampar.

Lampião era criticado em sua cidade natal como fraco e medroso porque nos embates com a polícia sua arma de batalha era a fuga e aguardava o melhor momento para atacar. Tinha um temperamento melancólico e sofria de crises hipocondríacas após suas derrotas. Tais informações fazem pensar a figura de Lampião como um frouxo? Não, ou será que se trata apenas da ruptura do modelo masculino que embasava seu mito? (PONZIO, 1995, p. 3-10). A imagem do homem mais sensível está mais próxima do conceito de feminilidade, característica contrária à virilidade anunciada. Temia-se em Lampião, sua sensibilidade, a possibilidade de outro modelo de ser homem.

A partir da busca de uma nova definição de sua virilidade, o homem depara-se com a ansiedade e faz uma confissão de desamparo. A crise atual do masculino é a crise de poder do macho. Confusos, eles buscam elementos exteriores para poder compensar seus elementos internos, seja através de trabalhos excessivos, sedução dom-juanesca (sem compromisso afetivo) seja através de malhação.

Paulo Roberto Ceccarelli (1998, p. 8), observou que nas teorias freudianas existe um silêncio sobre a masculinidade, como se possuir um pênis fosse a garantia da passagem do masculino à masculinidade. Ao contrário dos ritos iniciáticos que ocorriam em culturas antigas, para ser homem é preciso tornar-se homem, ou seja, o caminho para a masculinidade precisa ser conquistado. Ao mesmo tempo permanece sempre possível o risco de perdê-la.

Ritos violentos estão presentes em diversas culturas para possibilitar que um menino conquiste a masculinidade. Entre os Bimin-Kuskusmin, de 7 a 10 anos de idade, que vivem em Papua Nova Guiné, eles são flagelados com varas e urtigas e sofrem vômitos induzidos durante quatro dias com a finalidade de excluírem de seus organismos todos os elementos femininos que trazem desde o nascimento. Sofrem ainda um corte no umbigo para acabar com as últimas ligações com mãe, para só assim terem nomes masculinos (POOLE, 1982, p. 99 apud TREVISAN, 1998). Bourdieu traduz bem essa realidade. A virilidade como se vê, é uma noção eminentemente relacional, construída diante dos outros homens e contra a feminilidade, por uma espécie de medo do feminino (1999, p. 67). 
Para as meninas a passagem para a feminilidade é marcada pela primeira menstruação, ou seja, o feminino possui uma identidade mais configurada, pela sua relação com a natureza enquanto que o masculino depende do meio social, o que o torna fragilizado e ameaçado. Possuir um pênis não garante a virilidade. Ai encontra-se o drama identitário da masculinidade. Esta vai sendo construída diante do social e através da negação do feminino.

Essas tentativas patriarcais de amenizar, através do rito de iniciação, a passagem, para a masculinidade, acaba por reforçar o trauma do tornar-se homem, ao impor a severa oposição de tudo que possa vir a ser feminino. Desta forma, podemos dizer que a masculinidade é um gênero severamente vigiado, tanto pelo feminino, como pelo próprio masculino.

Paulo Roberto Ceccarelli (op. cit), afirma que a identificação com o pai constitui a chave para compreender a masculinidade, pois é o pai quem se encarrega da função de passar a virilidade ao filho. Entretanto essa relação pai-filho não é fácil, pois conforme a teoria edipiana de Freud, o menino tem com o pai uma relação ambivalente: sente ao mesmo tempo, amor ao protetor e ódio ao rival, marido da mãe.

Um dos grandes problemas identitários masculinos é a ausência paterna, já que o pai serve de imagem e inspiração para o filho. Sem esse referencial, o homem vai em busca de seu semelhante, para talvez, encontrar sua identidade. Para Ceccarelli (op. cit), a maturidade psicológica do filho só se completa quando ele ocupa o lugar do pai dentro de si mesmo. Quer dizer, o homem precisa matar simbolicamente o pai para encontrar sua identidade, mas acaba idealizando-o como a imagem daquele mistério buscado: o masculino. A possibilidade de tomar o lugar do pai constitui um dos motivos da incompletude básica do masculino e um dos principais motivos de sua crise gerando uma obsessiva necessidade de auto-afirmação.

Em Totem e Tabu (1913-1914, p. 144) Freud relata o mito:

"Certo dia os irmãos que tinham sido expulsos retornaram juntos,
mataram e devoraram o pai, colocando assim um fim a horda
patriarcal. Unidos, tiveram a coragem de fazê-lo e foram bem
sucedidos no que lhes teria sido impossível fazer individualmente [...]
o violento pai primevo fora sem dúvida o temido e invejado modelo
de cada um do grupo de irmãos e, pelo ato de devorá-lo, realizavam a
identificação com ele, cada um deles adquirindo uma parte de sua
força".

Compreendemos que isto possibilita uma relação com os dados de identificação do sujeito com seu pai. Os homens foram assumindo postura endurecida afastando-se da ternura e da amabilidade, dimensões identificadas com o feminino. A literatura aponta para a possibilidade da organização do masculino poder ser menos traumática quando diminuir a tensão do 
homem em possuir em seu interior, componentes femininos, refazendo o equilíbrio entre masculino e feminino, entre anima e animus.

James Hollis (1997, p. 154) sugere uma direção para a possível cura da ferida masculina: correr o risco de amar outros homens, já que o elemento passivo (o outro) está inserido no cerne do masculino. Ou seja, o masculino só decifrará seu enigma aprendendo simultaneamente a ser e não ser. $\mathrm{O}$ homem moderno encontra-se constrangido em eliminar o velho patriarca e reinventar o pai e a virilidade por ele outorgada. Kierkgaard, citado por Hollis, diz de que não é possível salvar nossa era enquanto ela não se convencer de que está perecendo. De modo análogo, não haverá mudança alguma se os homens não tomarem consciência de sua crise.

\section{Considerações finais}

Nossa intenção primeira com esta pesquisa foi, não apenas enfatizar os estudos sobre a masculinidade e sua relação com os modelos culturais impostos ao tornar-se homem, mas também verificar como esta relação é construída, se ela traz benefícios ou malefícios para a vida do homem em questão e sua relação com as condutas violentas. A partir deste trabalho questionamos o tipo de educação que se dá aos filhos homens, estimulando-os a não chorar, a serem sempre independentes e ligados ao mundo externo.

Os modelos postos pela cultura, plasmaram os jovens estudados, fazendo deles seres endurecidos, por uma decorrência da repulsa sugerida socialmente, a qualquer sentimento considerado feminino, seja ele de afeto, carinho, dependência ou fragilidade. $\mathrm{O}$ masculino construído revelou-se atravessado por atitudes misóginas, homofóbicas, homoafetivas e homoemocionais. Uma masculinidade construída tanto sob a negação do feminino como da recusa do sentimentalismo e do medo da homossexualidade.

Identificamos que houve para alguns participantes, situações de constrangimento, traumas ou níveis elevados de ansiedade e presença de comportamentos endurecidos como forma de resposta ao modelo cultural exigente de ser homem. Embora seja clara a insatisfação dos sujeitos com estes modelos impostos, é unânime, e para nós um paradoxo, a satisfação que eles revelam com suas construções masculinas. Condenam os modelos sim, mas acham-se adequados como homens, neles plasmados. Curiosamente recusam e reafirmam tais modelos, como se não pudessem perceber-se como homens, fora de seus parâmetros. Visto em linhas gerais, o trabalho aponta para uma inequívoca submissão aos modelos culturais. Ninguém se arrisca a ser avaliado de forma duvidosa por seus pares de cultura. Nas expressões é forte a 
recusa e constante a afirmação de que se faz necessário mudá-los. Essa ambivalência é lugar de angústia e desamparo. Como ser homem hoje, se não podem eles admitir sensibilidades em si, se não podem ter afeto por outros homens?

Encontramo-nos por fim, diante de uma masculinidade atravessada por contradições, mas uma masculinidade que responde ao propósito do ser homem nessa cultura: homem endurecido, sem nada que o aproxime do feminino, do emocional, sensível, estético ou terno. Quase todos apresentaram produção de condutas violentas, sobretudo quando alguém fala da mãe, ou de alguém querido. Outra fonte de violência é o fato de ser traído ou de ter sua moral abatida perante outrem.

Estávamos temerosas pelo fato de sermos mulheres pesquisando acerca da masculinidade. Também nos interrogávamos se isso interferiria na narrativa dos participantes. Contudo nos deparamos com o inverso, com uma abertura e disponibilidade sem constrangimentos por parte dos participantes para falarem de algo a que não estão acostumados, ou seja, a falar de si mesmos, de sua construção pessoal. Compreendemos que, afinal de contas, um homem não fala de suas dúvidas, inquietações, derrotas ou fraquezas para outro homem. Inclusive muitos deles agradeceram a oportunidade que tiveram de ser ouvidos, e pela possibilidade de falar de um assunto antes não falado ou questionado. Esse é um tema quase sempre colocado na ordem da obviedade, do indubitável com que é vista a masculinidade. Ela está construída através da obediência a um corpo rígido, sem emoção, dirigido para o número de conquistas, da independência financeira, não deixando margens a dúvidas.

\section{Referências bibliográficas}

BORIS, G. D. J. B. Falas de Homens. A Construção da Subjetividade Masculina. São Paulo/Fortaleza: Editoras Annablume e Secult, 2002.

CECCARELli, P. R. A Construção da Masculinidade, Percurso 19-2/ 1998, p. 49 a 56.Disponívelem: $<$ http://www.ceccarelli.psc.br/artigos/portugues $/ \mathrm{html} /$ aconstrucao.htm $>$ Acesso em 27/01/04.

CUSCHINIR, L. O Homem e suas Máscaras. Rio de Janeiro: Ed. Campus, 2001.

DORAIS, M. O Homem Desamparado. Crises Masculinas: Compreendê-las para Enfrentálas. Tradução de Yvone Maria de Campos Teixeira da Silva. São Paulo: Ed. Loyola, 1994.

FREIRE, J. A inútil dureza da condição masculina. Folha de S. Paulo, Caderno Mais, Domingo, p. 5-7, 18/02/1996.

FREUD, $\mathrm{S}$. IV O retorno ao totemismo na infância. Volume XIII. 
HOLLIS, J. Sob a Sombra de Saturno: a Ferida e a Cura dos Homens. São Paulo: Paulus, 1997.

NOLASCO, S. O Mito da Masculinidade. Rio de Janeiro: Rocco, 1993.

POLLACK, W. Meninos de verdade: Conflitos e desafios na educação de filhos homens. 1a ed. São Paulo: Alegro, 2000.

PONZIO, A. F. Ex-cangaceira narra morte de Lampião, Folha de S. Paulo, 30 de julho de 1995.

TREVISAN, J. S. Seis Balas num Buraco Só: A Crise do Masculino. Rio de Janeiro: Record, 1998. 